\title{
REFLEXÕES SOBRE LEI E INCONSCIENTE, PODER E FORÇA-VIOLÊNCIA E CONEXÕES COM O ATO POLÍTICO-PEDAGÓGICO DE EMANCIPAÇÃO, COM BASE EM SLAVOJ ZIZEK
}

\author{
Hildemar Luiz Rech ${ }^{1}$ \\ Maria Anita Vieira Lustosa ${ }^{2}$
}

Resumo: Para Zizek, a ideia de uma forma vazia da lei, para além de suas encarnações positivas, remete à sua afirmação como inconsciente e como indício de um conteúdo recalcado. Por outro lado, sobre a força como violência cabe observar que ela se encontra tanto na fundação quanto na conservação do poder. Por outro lado, a dimensão subjetiva da violência deve ser interpretada em termos de sua articulação com as dimensões simbólica, e objetiva (ou sistêmica) da violência e não como um fenômeno isolado. Quanto à educação, cabe observar que, na perspectiva de Zizek, o ato pedagógico precisa ter uma afinidade eletiva com o ato político que rompe com os significantes mestres imbricados com o fetichismo da mercadoria e com a forma social do capital. Ou seja, o sujeito para ser livre e emancipado deve transcender e romper com as coordenadas sistêmicas do capital, mediante um engajamento que se coloca a contrapelo da rede simbólica alienante e na contramão da reificação e do estranhamento nas relações sociais. Isto implica o desvencilhar-se de uma subsunção e de um aprisionamento do sujeito em dispositivos institucionais, normativos e tecnológicos de controle e de autocontrole, sintonizados com a reprodução do capital. Em síntese, somente quando os processos de subjetivação apresentam uma afinidade eletiva com uma práxis teórica e social que se exprime mediante uma atividade coletiva criativa, livre e soberana é que pode ocorrer um processo de emancipação individual e social.

Palavras-chave: lei, poder, força-violência, e ato político-educativo.

ABSTRACT: For Zizek, the idea of an empty form of the law, beyond its positive incarnations, points to its affirmation as unconscious and as one trace of repressed content. On the other hand, concerning to the force as violence, it's up to point out that it's anchored as much on the foundation as on the conservation of the power. Moreover, the subjective dimension of violence must be interpreted in terms of its articulation with the symbolic and objective (or systemic) dimension of violence, and not as one isolated phenomenon. As regards to education, it's appropriated to observe that, accordingly the point of view of Zizek, the educational act needs to have an elective affinity with the political act, which breaks off with the master significant overlapped with the commodity fetishism and with the social form of capital. That's to say, one subject for to be free and emancipated, he needs to transcend and break off with the systemic coordinates of capital, through a commitment which is placed against the alienating symbolic network and counter-positioned to "reification" and strangeness in social relations. This implicates to get rid of a submerging and an imprisonment of the subject in institutional, prescriptive and technological arrangements and devices of control and

\footnotetext{
${ }^{1}$ Doutor em Ciências Sociais pelo IFCH da UNICAMP, SP, com estágio doutoral (como Visiting Researcher) na Universidade de Manchester, Inglaterra; Pesquisador e Professor Associado IV no Departamento de Fundamentos da Educação e na Linha de Pesquisa de Filosofia e Sociologia da Educação no Programa de Pós-Graduação em Educação, FACED-UFC. E-mail: hluizrech@gmail.com

${ }^{2}$ Doutora em Educação Brasileira pela Universidade Federal do Ceará (UFC). Professora do Curso de Pedagogia da Universidade Estadual do Ceará - UECE. Técnica do Grupo de Pesquisa: "Laboratório Marxista de Pesquisas e Estudos sobre Juventude e Trabalho - LAMPEJU”, vinculado ao IFPB. E-mail: anita_lustosa@hotmail.com
} 
self-control, which are getting on with the reproduction of capital. In a synthetic explanation we can say that only when the subjective process presents an elective affinity with a theoretical and social praxis, which is expressed through a creative and collective and a free and sovereign activity, it's possible to occur an individual and social process of emancipation.

Key-words: law; power; force-violence; and political-educational act.

\section{Notas sobre Lei, Poder e Força-Violência, na perspectiva de Slavoj Zizek}

A abordagem crítica da força como violência em Zizek (2014) tem uma afinidade eletiva com o pensamento de Walter Benjamin, tanto que para o filósofo esloveno a violência fundamental que assegura o funcionamento normal do Estado é a violência mítica, assim como concebida pelo filósofo berlinense das imagens dialéticas. Por outro lado, para Zizek (2014), também a ideia benjaminiana da violência divina é a forma fundamental de violência capaz de minar e romper com os significantes mestres que estruturam a rede simbólica alienante e com as coordenadas estruturais da violência sistêmica. Pois, ambos estes últimos estão estruturalmente inscritos de modo oculto na dinâmica do próprio Estado capitalista, na forma mercadoria e nas relações de troca do mercado capitalista. Portanto, os agentes estatais, em relativa afinidade com os agentes do capital, atuam de forma brutalmente repressiva e reativa quando se trata de proteger as regras sistêmicas e simbólicas da dominante vigente. Sob este prisma, segundo Zizek (2014), a violência nunca deve, em sua complexidade, ser vista de modo reducionista como mera violência subjetiva. Ou seja, em sua forma mais complexa e fundamental a violência jamais se restringe isoladamente o seu aspecto físico diretamente visível. A violência física direta que se circunscreve apenas a uma "passagem ao ato" avessa ao simbólico, exprime nada mais que uma atitude reativa que mantém as coordenadas sistêmicas intactas e, como tal, é mantenedora do status quo. Ou seja, sob este aspecto meramente subjetivo a violência exprime uma forma de total impotência política.

Por outro lado, para que a violência possa ser revolucionária ela deve inserir-se no combate permanente contra a cristalização ou ossificação das estruturas do Estado e contra a dinâmica sistêmica intrínseca ao capitalismo. Ou seja, e é imprescindível que se estabeleça uma dissolução de todas as formas de vida ditadas pela reprodução capitalista. Enfim, isto implica em que o sujeito consiga lidar com a difícil situação de sustentar-se, em um momento de rompimento com a rede simbólica alienante - com seus significantes mestres alienantes - em termos de seu próprio vazio constitutivo

\begin{tabular}{|c|c|c|c|}
\hline Qovista Dialectus & Ano 3 & n. 9 & Setembro - Dezembro 2016 \\
\hline
\end{tabular}


básico, ou seja, como partícula vazia do próprio Real traumático. E é apenas, em um segundo momento que podem ser afirmados novos significantes mestres, associados a novos significantes comuns do saber, sintonizados com uma perspectiva social e política afinada com um processo de emancipação individual e coletiva.

Em sua abordagem paraláctica da violência, Slavoj Zizek (2014) chama a atenção para as suas múltiplas dimensões, quais sejam: a simbólica, a objetiva (sistêmica) e a subjetiva. Dimensões estas que não devem ser focadas de modo fechado e isolado, mas devem ser abordadas sob o prisma de seu entrelaçamento recíproco.

Por outro lado, segundo Zizek (2009a), diante da questão da violência da lei e do poder, também não se pode desconhecer a novidade radical, para a abordagem de tal problemática, contida na concepção kantiana da Lei moral. Ou seja, a lei kantiana não é uma simples forma vazia que se aplica a um conteúdo empírico determinado a fim de assegurar que esse conteúdo encontre os critérios de adequação ética. Enfim, a forma vazia da Lei funciona antes como a promessa de um conteúdo ausente que nunca está por vir. Essa forma não é o molde neutro-universal da pluralidade dos diferentes conteúdos empíricos, mas atesta o fato de uma incerteza persistente quanto ao conteúdo dos nossos atos. Portanto, nunca sabemos se o conteúdo determinado, que presta contas da especificidade de nossos atos, será o correto, ou seja, nunca sabemos se agimos efetivamente de acordo com a Lei e não fomos guiados por motivações patológicas ocultas. Enfim, segundo Zizek (2009a, p.362):

Kant anuncia assim a noção de Lei que encontra seu ponto culminante em Kafka e na experiência do moderno "totalitarismo" político: visto que no caso da Lei [onde o seu Dass-Sein (o fato da Lei) precede o seu Was-Sein (o que é essa Lei)] o sujeito encontra-se numa situação em que, apesar de saber que existe uma Lei, ele nunca sabe (e a priori, nunca pode saber) o que é essa Lei. [Pois há] uma distância exata que separa sempre a Lei das suas encarnações positivas. Por conseguinte, o sujeito é, a priori, na sua própria existência culpado: culpado, sem sequer saber de quê (e culpado por isso mesmo), [quando está] infringindo a lei sem sequer conhecer as suas regulações exatas. Segundo Zizek, o que temos aqui, e pela primeira vez na história da filosofia, é a afirmação da Lei como inconsciente: a experiência da Forma sem conteúdo é sempre indício de um conteúdo recalcado, ou seja, quanto maior for a intensidade com que o sujeito adere à forma vazia, mais traumático se torna o conteúdo recalcado. 
Assim, essa ausência da Lei - enquanto um conjunto determinado de normas positivas universais - torna ainda mais forte a pressão insuportável que a Lei moral exerce, “[...] na medida em que ela pressiona, como pura injunção vazia, para que cada um cumpra o seu Dever. Assim, [...] é aqui que encontramos a distinção crucial entre as regras a inventar e a Lei/Interdito que as apoia” (ZIZEK, 2009a, p.363).

Portanto, quando a Lei falha em apresentar-se "como conjunto de normas universais simbólicas é que a encontramos na sua forma mais radical, a Lei sob o aspecto do Real de uma injunção incondicional" (ZIZEK, 2009a, p.363).

Desse modo, segundo Zizek (2009a, p.363):

Se lermos Kant em termos psicanalíticos, a distância entre as regras que inventamos e a Lei que as sustém não é senão a distância entre regras (conscientemente pré-conscientes) que seguimos e a Lei como inconsciente: a lição básica da psicanálise é que, na sua forma mais radical, o Inconsciente não é a multiplicidade dos desejos ilícitos "reprimidos", mas $a$ própria Lei fundamental.

Sob este aspecto, mesmo um sujeito bastante narcísico é apoiado, em termos de seu uso dos prazeres, "pela injunção incondicional inconsciente de um superego que lhe ordena que goze" (ZIZEK, 2009a, p.363).

Por conseguinte, o sujeito, quando infringe a lei sem conhecer efetivamente as determinações dessa lei, sente-se culpado, ou seja, sofre uma recriminação interna que lhe traz um forte mal-estar. Em decorrência disso, segundo Zizek (2008), é preciso que se estabeleça uma cisão entre a Lei pública e seu complemento superegóico obsceno, pois, é isso que nos faz confrontar o próprio âmago da paralaxe político-ideológica:

A lei pública e seu complemento superegóico não são duas partes diferentes do edifício legal, são o mesmo e o único "conteúdo" - com uma pequena mudança de ponto de vista, a Lei digna e impessoal assemelha-se a uma máquina obscena de jouissance (gozo). [E com] outra leve mudança e [o que ocorre é que] as regulações legais, que prescrevem nossos deveres e garantem nossos direitos, parecem ser a expressão de um poder impiedoso cuja mensagem a nós, súditos, é: "Posso fazer o que quiser com vocês!" (ZIZEK, 2008, pp.437-438).

O mestre inimitável dessa mudança paraláctica em relação ao edifício do poder legal foi Kafka, pois foi ele que primeiro percebeu “[...] uma máquina gigantesca de 
jouissance [de mais-gozar obsceno] no que antes parecia um digno edifício da Ordem legal” (ZIZEK, 2008, p.438). Ademais, ainda segundo Zizek (2014, p.78):

O verdadeiro contrário do amor-próprio egoísta não é o altruísmo, a preocupação com o bem comum, mas a inveja, o ressentimento, que me faz agir contra os meus próprios interesses. Freud sabia muito bem disso: a pulsão de morte opõe-se tanto ao princípio de prazer como ao princípio de realidade. O verdadeiro mal, que é a pulsão de morte, implica a auto-sabotagem. Faz com que ajamos contra os nossos próprios interesses.

A propósito, nas palavras de Zizek (2014, p.78), o problema do desejo humano é, no sentido lacaniano, ser sempre "desejo do Outro", em todos os sentidos do termo: “desejo pelo Outro, desejo de ser desejado pelo Outro, e, especialmente, desejo daquilo que o Outro deseja. Este último desejo torna a inveja, que inclui o ressentimento, uma componente constitutiva do desejo humano".

Por outro lado, ainda sob este aspecto, tanto Kafka, quanto a psicanálise lacaniana nos alertam para a existência de uma máquina gigantesca de mais-gozar obsceno, a qual se imbrica, sob um mesmo e único "conteúdo", com as formas públicas da lei no cerne do mesmo edifício legal. Portanto, desse modo, a Lei digna e impessoal enlaça-se com uma máquina obscena de gozo, implicando o excesso da pulsão de morte.

Assim, segundo Zizek (2014), a própria psicanálise reintroduz de modo pertinente as noções do mal e da responsabilidade no discurso ético, nos lembrando que é a "pulsão de morte" que nos perturba ao buscarmos de modo racional o prazer, funcionando como uma estranha inversão que nos leva a sabotar nossos próprios interesses. Sob este prisma, o signo da inveja, a exigência de justiça é que o gozo excessivo do Outro seja limitado, do modo que todos tenham um acesso igualitário ao gozo. Ou seja, o sujeito não inveja a posse pelo Outro do objeto investido, enquanto tal. Antes a inveja dirige-se mais ao modo como o Outro é capaz de gozar o seu objeto, e é por isso que não basta roubar-lhe o objeto, devendo o alvo dirigir-se à destruição da aptidão/capacidade do Outro de gozar o objeto. Para Zizek (2014, p.79-80):

O desfecho necessário desta exigência é, evidentemente, o ascetismo. Uma vez que não é possível impor uma jouissance [Gozo] igual, o que é imposto, em vez de uma igual partilha, é a proibição. Hoje, na nossa sociedade alegadamente permissiva, esse ascetismo, contudo, assume a forma do seu contrário, isto é, a de uma injunção superegóica generalizada - o mandamento 
que nos intima: "Goze". Estamos todos enfeitiçados por tal injunção. O resultado é que nosso gozo nunca foi tão tolhido. Pensemos no [ascetismo hedonista do] yuppie que combina a "autorrealização" narcísica com essas disciplinas extremamente ascéticas que são praticar corrida [o jogging], alimentar-se de forma saudável, etc.

Sob esta perspectiva, pode aqui também ser relembrada a leitura de Antígona proposta por Lacan, na qual se insere a chave do seu "Kant com Sade. A propósito, segundo Zizek (2014, p.152-153):

Hoje, na nossa era pós-idealista da "hermenêutica da suspeita", nós não sabemos todos que a chave do avec ("com") [do Kant com Sade] está em significar que a verdade do rigorismo ético de Kant é o sadismo da lei? Ou seja, que a lei kantiana é uma instância superegoica que goza sadicamente o impasse do sujeito, a sua incapacidade de corresponder às suas exigências inexoráveis, à semelhança das do proverbial professor que tortura os alunos fixando-lhes tarefas impossíveis e secretamente saboreia os seus fracassos. E, todavia, o que Lacan nos diz é exatamente o oposto dessa primeira associação: não era Kant um sádico disfarçado, mas Sade é que era um kantiano disfarçado. $\mathrm{O}$ que significa que devemos ter mente que o tema fulcral de Lacan é sempre Kant, não Sade: o que lhe interessa são as consequiências últimas e as premissas negadas da revolução ética kantiana.

Ou seja, Lacan não apresenta afinidade com posições reducionistas que vêem qualquer ato ético como tendo por origem uma motivação patológica. De modo bem diferente, como observa Zizek (2014, p.153):

O tema fulcral do interesse de Lacan reside antes na inversão paradoxal através da qual o próprio desejo (ou seja, o agir segundo o nosso próprio desejo, sem o comprometer) não pode mais ter por origem qualquer interesse ou motivação de ordem 'patológica', e por isso corresponde aos critérios do ato ético kantiano, de tal modo que 'seguir o próprio desejo' coincide com 'fazer o próprio dever'. É por isso que Lacan, na sua acepção de ato, inverte a 'hermenêutica da suspeita' estabelecida: quando o próprio Kant, movido pela suspeita, admite que nunca podemos saber ao certo se o que fizemos foi um verdadeiro ato ético, não sustentado em segredo por algum motivo patológico (ainda que esse motivo seja a simples satisfação narcísica decorrente do fato de termos feito o nosso dever), incorre então em erro. O que é verdadeiramente traumático para o sujeito não é o fato de um puro ato ético ser 
(talvez) impossível, de a liberdade ser (talvez) uma aparência, baseada na ignorância das verdadeiras motivações dos nossos atos; o que é verdadeiramente traumático é a própria liberdade, o fato de que a liberdade é possível, e de nós procurarmos desesperadamente estas ou aquelas determinações 'patológicas' a fim de evitarmos este fato. Para dizê-lo de outra forma, a verdadeira teoria freudiana nada tem a ver com a redução da autonomia ética a uma ilusão baseada na repressão dos nossos 'baixos' motivos libidinais.

Enfim, quando concebemos o ato ético para além do princípio de realidade, nos confrontamos com o "realismo" pós-moderno cuja posição inerente é que a realidade "é apenas o resultado de certo conjunto historicamente específico de práticas discursivas e mecanismos de poder. Aqui a crítica ideológica das ilusões em nome da realidade é universalizada e invertida em seu oposto: a própria realidade é a ilusão suprema" (ZIZEK, 2013, p.116). Enfim, segundo Zizek (2013, p.117):

A lição que tiramos desse paradoxo diz respeito à oposição entre realidade e Real: desprovida do núcleo duro do Real, daquilo que resiste à simples integração na realidade comum (simbolização, integração em nosso universo), a própria realidade se transforma em uma tessitura maleável, indefinidamente plástica, que, precisamente, perde o caráter o caráter da 'realidade' e se transforma em efeito fantasmático das práticas discursivas. $\mathrm{E}-\mathrm{o}$ anverso do mesmo paradoxo - a experiência definitiva do Real não é da 'realidade' que destrói as ilusões, mas a de uma 'ilusão' que persiste 'irracionalmente' contra a pressão da realidade, não cedendo à 'realidade'. [Assim,] O futuro de uma ilusão de Freud é que a ilusão tem um futuro não porque as pessoas não conseguem aceitar a dura realidade e precisam de falsos sonhos, mas porque as 'ilusões' são sustentadas pela insistência incondicional de uma pulsão que é mais real que a realidade.

Por outro lado, retomando aqui o foco sobre a questão da violência, cabe observar que, conforme Zizek (2014), ela emerge do campo simbólico da linguagem; da dimensão objetiva (ou sistêmica) de base estrutural e histórico-social; e da própria subjetividade humana. Portanto, é a partir de uma complexa e tríplice multiplicidade paraláctica de pontos de incidência que Zizek aborda a noção de violência.

Primeiro temos, segundo o autor (2014), uma violência simbólica que é o tipo mais decisivo e fundamental de violência. Esta dimensão da violência encarna a linguagem e suas formas, desde o cerne do registro simbólico. E, como tal, ela envolve

\begin{tabular}{|l|l|l|l|l|}
\hline Qonista Qialectus & Ano 3 & n. 9 & Setembro - Dezembro 2016 & p. 46 - 61 \\
\hline
\end{tabular}


os significantes mestres e os significantes do saber, que se exprimem via sujeito da enunciação inconsciente, os quais, porém, incidem sobre a conformação de um determinado universo de significado que, ademais, é socialmente construído e, sob este aspecto, relacionado ao sujeito do enunciado. A violência simbólica, exercida pela classe dominante - mediante um discurso de controle ideológico-hegemônico atado à reprodução ampliada do Capital e de suas relações sociais de produção -, impacta sobre a identidade das classes e frações da classe dominadas e exploradas. Da mesma forma, segundo Zizek (2014), o discurso racista, de que os negros são inferiores aos brancos, afeta e cerceia a identidade sócio-simbólica dos negros, tornando os negros realmente inferiores na sociedade, de modo que a violência exercida mediante a linguagem é efetiva e eficiente. Enfim, a violência simbólica que se articula a partir das próprias estruturas da linguagem, além de incidir sobre as práticas econômicas de reprodução social, funciona, portanto, também como dispositivo ideológico discursivo extraeconômico que costura e amarra a reprodução sócio-cultural e sócio-política na sociedade capitalista. Esta função extra-econômica exercida mediante diversos dispositivos de violência simbólica é algo indispensável à dinâmica contemporânea do capitalismo globalizado, pois este não conseguiria completar o seu ciclo de reprodução social, sem o apoio em dispositivos normativos, burocrático-institucionais, midiáticos, tecnológicos de controle e ideológico políticos e culturais.

Uma segunda dimensão da violência, segundo Zizek (2014), se configura como violência objetiva ou sistêmica, que aparentemente é menos visível, mas que é crucial para se captar criticamente a complexa articulação com as demais formas ou dimensões da violência. Esta forma é inerente ao que imaginariamente é percebido como estado normal e pacífico das coisas. A propósito, a violência objetiva deve ser compreendida a partir de um lastro estrutural e histórico. Ela é relacionada às próprias coordenadas sistêmicas da ordem social capitalista atual e à dinâmica histórica do capital.

O fetichismo da mercadoria e da mercadoria-imagem; o valor de troca e a lei do valor entrelaçados com a produção e apropriação da mais valia; o crescente poder do capital financeiro (em sua articulação com o capital industrial-produtivo, com o setor de serviços e com a dinâmica da sociedade de consumo) são fatores que, ao mesmo tempo em que conformam o mercado capitalista, elas incidem sobre e condicionam constrangedoramente as práticas sociais cotidianas. Estes, portanto, são igualmente aspectos da violência sistêmica. As coordenadas sistêmicas apresentam ainda outra dimensionalidade estrutural oculta, anônima e inconsciente de antagonismo social,

\begin{tabular}{|l|l|l|l|l|}
\hline Q & Dovista \\
\hline
\end{tabular}


articulada desde o cerne de um núcleo contraditório fundamental que é a "luta de classes". Esta divisão social fundamental de classes exerce uma força constritora e lapidadora sobre as demais diferenças sociais, étnicas, raciais, de gênero, religiosas e culturais. Enfim, este cerne funciona com uma divisão social e política estrutural anônima, que superdetermina o arranjo dinâmico das relações de exploração e dominação social e as relações de força política na sociedade.

Uma terceira dimensão da violência, visualizada por Zizek (2014), é a violência subjetiva, que é a mais visível das formas de violência. Mas ela é visualizada de forma equívoca quando não abordada a partir da articulação complexa que a envolve com as demais dimensões da violência, quais sejam, a simbólica e a objetiva (ou sistêmica). O elemento que a caracteriza é o fato de ela se exprimir mediante os atos de determinados agentes sociais explicitamente identificáveis, que perturbam o aparente estado normal e pacífico das coisas no contexto sócio-político da sociedade.

Desse modo, segundo Zizek (2014), a violência subjetiva se articula em torno de práticas sociais autoritárias (ou agressivas) fundamentalistas, envolvendo turbas fanáticas. Ademais, ela também pode se configurar a partir de agentes sociais engajados em aparelhos repressivos disciplinados, ou a partir de associações privadas legais e ilegais que espalham ações violentas que provocam o terror e o medo. Ela pode, igualmente, emergir como atos violentos com motivações criminosas, perpetrados por indivíduos malévolos. Enfim, ela pode também brotar enquanto atos isolados de violência, com traços de "anormalidade" ou patológicos; ou, mesmo, enquanto práticas reativas de ressentimento e de desespero social, sem nenhuma visualização alternativa ou revolucionária de sociedade. Enfim, é fundamental que não se visualize a violência subjetiva como um fetiche. Ao contrário, a tarefa central é compreender a complexa interação das três dimensões da violência: a subjetiva, a objetiva e a simbólica.

O capitalismo globalizado contemporâneo, para fazer frente à sua crise de legitimidade e de acumulação ampliada, necessita recorrer a sutis e sofisticadas formas complementares de dominação político-social, para manter em movimentação acelerada a dinâmica dos fluxos do mercado. E, em um quadro de afirmação do paradigma tecnológico da automação e da digitalização, acompanhado por práticas de gestão flexíveis e fragmentárias, um dos recursos adotados é o consumismo artificialmente induzido a crédito sob a emulação do reino da mercadoria-imagem, da propaganda, do marketing e da marca dos produtos. Enfim, as práticas sociais capitalistas ostentam o fetichismo da mercadoria imagem e a lei do valor como seu núcleo articulador e 
dinamizador. Portanto, mecanismos extra-econômicos de controle, sedução, alienação e de absorção funcionam como elementos de captura da subjetividade dos indivíduos em prol da meta da reprodução ampliada do capital.

De outro lado, segundo Zizek (2014), cabe enfatizar a proliferação de formas pós-políticas e biopolíticas de controle social que se articulam em torno da gestão do medo. Nestas circunstâncias, o próprio Estado concentra as suas forças, prioritariamente para garantir o livre fluxo das mercadorias materiais (e imateriais) no mercado. Assim, as políticas públicas e sociais voltadas para o bem-estar, a segurança e a dignidade dos cidadãos tornam-se cada vez mais limitadas e desintegradas, sendo progressivamente substituídas por "biopolíticas" pós-políticas de administração da "vida nua".

Desde o cerne desta perspectiva, as relações sociais ficam mais e mais assimétricas, desiguais e opacas, além de esvaziadas de qualquer compromisso ético e de solidariedade. Assim, a própria linguagem fica mais intensamente impregnada pela violência. Ou seja, as pessoas podem conviver socialmente, lado a lado, a partir de perspectivas bem diferentes, manifestando a maior indiferença umas com as outras, permitindo-lhes, ademais, reproduzir sutilmente, mediante o próprio discurso ideológico da tolerância sócio-cultural, práticas veladas de preconceito e de segregação social.

Além disso, segundo Zizek (2014), no universo da pós-política contemporânea, importantes categorias políticas e sociológicas, como exploração, dominação, marginalização social e desigualdade se tornam cada vez mais recalcadas. Ou seja, isto ocorre, enfim, porque o discurso ideológico dominante passa a se articular em torno da noção de tolerância. Assim, no cerne do processo de culturalização fragmentadora da política contemporânea, a polarização antagônica fundamental que é a luta de classes vem a ser substituída pelo discurso ideológico das diferenças culturais.

Ademais, no que tange ao conceito de universalidade, Zizek (2014), entende que este somente passa a adquirir sua eficácia simbólica ou a sua verdadeira efetividade quando ele irrompe como dimensão universal do próprio cerne de uma realidade particular, que se experimenta como universal. A propósito, para o autor, não são as culturas com suas identidades próprias que se dão as mãos na luta pela emancipação. Mas, são as partes de parte nenhuma de cada cultura, enfim as partes recalcadas, exploradas, condenadas ao sofrimento de cada sociedade que ao se juntarem numa luta partilhada, podem abrir a sociedade para perspectivas efetivas de emancipação social.

Finalmente, retomando aqui o conceito de violência divina de Walter Benjamin, cabe relembrar aqui que esta concepção, segundo Zizek (2014), tem um sentido oposto

\begin{tabular}{|l|l|l|l|l|}
\hline Qonista Qialectus & Ano 3 & n. 9 & Setembro - Dezembro 2016 & p. 46 - 61 \\
\hline
\end{tabular}


ao da violência mítica, a qual funciona como meio para afirmar o Poder e o governo da lei. Sob esta perspectiva, a violência divina é um domínio exterior ao poder legal instituído, de modo a funcionar como um excesso pulsional de vida que se manifesta na história. Ou seja, a violência divina corresponde às intrusões explosivas de uma justiça para além da lei mítica e, como tal, ela não serve como meio para restabelecer o equilíbrio da justiça, mediante a punição dos culpados. Ela antes é o signo que denuncia a injustiça em um mundo eticamente desarticulado. Portanto, o lugar da violência divina é o dos extratos sociais longamente violentados simbólica, objetiva e subjetivamente. Enfim, em seu excesso vital, a violência divina - carregada de expectativas de liberdade e de emancipação - rompe a contrapelo da obscenidade de outro excesso eivado de conseqüências catastróficas, que é o do poder dominante.

Ainda, de outro ângulo, Zizek (2014), aponta para a ambigüidade da Lei, destacando que, se no nível positivo do direito ela se encontra entrelaçada e comprometida com o poder do Estado, de outro lado, ao nível do inconsciente psíquico, ela emerge na forma de interdito inconsciente incondicional. Para Zizek (2009b, p.143):

[A lei se situa] ao nível subterrâneo do superego, [no qual] a mensagem pública de responsabilidade desdobra-se na mensagem obscena do exercício incondicional do poder: as leis não me atam de fato, pois eu posso fazer-vos o que quero; tratarvos como culpados se assim decidir; destruir-vos com uma só palavra... Este excesso obsceno é um elemento constitutivo necessário à noção de soberania. A assimetria é aqui estrutural, ou seja, a lei não pode manter a sua autoridade se os sujeitos aí não ouvirem o eco da auto-asserção obscena incondicional. E a violência divina do povo é correlativa deste excesso de poder. Ela é a contrapartida deste, dirigida completamente contra ele visando miná-lo.

Por outro lado, Zizek (2011a) coloca a necessidade de que se instaure a emergência do autêntico ato político para que se concretize uma efetiva ruptura com as coordenadas da ordem social violenta e injusta. Sob este prisma, segundo Zizek, o ato político somente pode ocorrer no momento em que o pensamento e a ação do sujeito se desprendem das coordenadas da rede simbólica alienante, e se atam à atividade coletiva, traduzindo-se em uma ação política soberana, sem fixação institucional imediata à intervenção política. Assim, o ato político instaura sua própria legalidade, suspendendo a Lei do poder opressor imperante, abrindo desta maneira espaços para a instauração qualificada de um processo de emancipação econômico-social, cultural e política.

\begin{tabular}{|l|l|l|l|l|}
\hline Qevista Dialactus & Ano 3 & n. 9 & Setembro - Dezembro 2016 & p. 46 - 61 \\
\hline
\end{tabular}


Esta leitura de Zizek a respeito do ato político não encarna, a princípio, nenhuma substância positiva inicial. Ela, parte, antes da irredutibilidade negativa do inconsciente que no sujeito se define por resistir aos processos de identidade e de autoreflexão. Portanto, este enfoque ancora-se no tema do descentramento do sujeito do inconsciente. "Descentramento, que indica a posição de não-identidade que um conceito não substancial de sujeito sempre sustentará diante dos espaços de representação, de auto-apreensão reflexiva e de identificação social” (ZIZEK, apud SAFATLE, 2003, p.182).

Nesta perspectiva, para Zizek, o sujeito denota uma partícula de liberdade, de modo que ele é intrinsecamente político, se encontrando em uma situação sempre aberta de inadequação e de superação. Em outras palavras: "O sujeito é aquilo que nunca é totalmente idêntico a seus papéis e identificações sociais" (SAFATLE, 2003, p.183).

De modo efetivo, as políticas de identidade acabam também fazendo o jogo da ideologia e, por conseguinte, do capital. Pois, o capital acomoda-se muito bem às políticas de identidade e à multiplicidade de identidades. Sob este prisma, a negatividade, na forma de uma universalidade não substancial e na forma de nãoadequação pode contrapor-se à falsidade da universalização da política da identidade: “A verdadeira escolha livre é aquela na qual eu não escolho apenas entre duas ou mais opções no interior de um conjunto prévio de coordenadas, mas escolho mudar o próprio conjunto de coordenadas" (ZIZEK, apud SAFATLE, 2003, p.185).

Enfim, o ato político rima com uma violência redentora bejaminiana:

Há um abismo entre o 'fundamentalismo ' religioso [ou político] fanático e a intervenção revolucionária autêntica, ainda que ambos pareçam compartilhar um caráter radical. Esse abismo não se refere apenas à dimensão sócio-política, mas também à estrutura imanente do ato: o ato fundamentalista é realizado para o [gozo] do 'grande Outro'; nele o sujeito instrumentaliza-se [e imola-se] para o 'Outro'. [Já o ato político], como um ato autêntico se autoriza apenas em si - ou seja, ele não é coberto pelo 'grande Outro'; pelo contrário, intervém no ponto exato da inconsistência [deste último]. Essa distinção é a diferença [entre a falsa pureza do supereu obsceno e a pureza ética autêntica], entre Kant e Sade: Sade não é simplesmente a verdade de Kant; a posição perversa sadiana emerge, em vez disso, quando a postura ética kantiana radical está comprometida" (ZIZEK, 2005, p.261). 
Sob este enfoque, todo ato político revolucionário é incondicional. Mas, não se trata de um "ato incondicional" situado fora da história e fora do simbólico, mas simplesmente de um ato surpreendente que é irredutível ao parâmetro e à moldura das condições dadas. Como destaca Zizek (2011a, p.311):

[O] ato não só está enraizado em suas condições contingentes, como são essas mesmas condições que fazem dele um ato: o mesmo gesto, realizado num momento errado - cedo ou tarde demais -, [deixa de ser, ou] não é mais um ato. Aqui o paradoxo propriamente dialético é que aquilo que torna $o$ ato "incondicional" é sua própria contingência: se o ato foi necessário, isso significa que foi totalmente determinado pelas condições, e pode ser deduzido a partir delas [...]. O vínculo entre a situação e o ato político, portanto, é claro: longe de ser determinado pela situação [...], o ato é possível em razão do não fechamento ontológico, [...] das lacunas de uma situação.

Portanto, no ato de liberdade e de emancipação o agente revolucionário não pede permissão ou não fica refém a alguma imagem ou ao gozo capturador e mortífero do “grande Outro". Ademais, o ato político revolucionário não pede permissão a nenhum Outro disfarçado de legitimação/autorização liberal-democrática de nossos atos, ao contrário, o ato se autoriza por si mesmo com base em sua própria Causa.

\section{A título de fechamento do texto: sintetizando algumas questões acima arroladas e tecendo uma conexão com a educação}

Para fechar a presente reflexão, referente ao pensamento de Slavoj Zizek, cabe observar que, segundo este autor, uma distância exata sempre separa a lei de suas encarnações positivas. Ou seja, a idéia de uma forma vazia da lei sem conteúdo remete à afirmação da lei como inconsciente e como indício de um conteúdo recalcado.

Assim, a inexistência de um conjunto determinado de normas positivas universais torna a lei moral uma pura injunção vazia que pressiona cada indivíduo a cumprir seu dever. Segundo Zizek (2009a), a lei/Interdito inconsciente, sobre a qual se apóia toda e qualquer regra positiva a inventar, supõe uma distinção crucial e uma distância na forma de um hiato entre o conjunto positivo de leis simbólicas universais e a Lei enquanto interdito inconsciente. Como nos esclarece a psicanálise, o próprio Inconsciente, em sua forma mais radical, não é a multiplicidade dos desejos ilícitos "reprimidos", mas a própria Lei fundamental. A propósito, encontramos este interdito 
inconsciente como o Real traumático de uma injunção incondicional, sempre quando a Lei falha em apresentar-se como conjunto positivo de normas universais simbólicas.

Em decorrência disso, segundo Zizek (2008), é preciso que se estabeleça uma cisão entre a Lei pública e seu complemento superegóico obsceno, pois, é isso que nos faz confrontar o próprio âmago da paralaxe político-ideológica. Contudo, estas duas dimensões da lei não são duas partes diferentes do edifício legal, pois elas são o mesmo e o único "conteúdo". Ou seja, com um pequeno deslocamento de ponto de vista, a Lei digna e impessoal assemelha-se a uma máquina obscena de jouissance (gozo). Então sob este prisma é preciso reunir condições ético-subjetivas e políticas de rompimento com as formas de conduta sintomaticamente patológicas encalacradas com as práticas sociais inconscientes que reproduzem a forma social do capital e o fetichismo da mercadoria e de seu equivalente geral. Somente desse modo pode emergir um rompimento com a compulsão repetitiva (wiederholungszwang) que reproduz a reificação e o estranhamento nas relações sociais.

Por sua vez, a violência apresenta, para Zizek (2014), três dimensões - a simbólica, a objetiva (ou sistêmica) e a subjetiva - que apenas sob o prisma de um corte epistemológico e analítico podem ser abordadas de modo separado. As dimensões cruciais e decisivas da violência são a simbólica (relacionada à estrutura da linguagem) e a sistêmica (relacionada ao cerne das coordenadas sistêmicas e histórico-sociais das formações econômico-sociais, políticas e culturais). Ambas, de modo imbricado, prédefinem o leque de escolhas econômicas, políticas e culturais disponíveis aos sujeitos. Por fim, temos a violência subjetiva, que é aquela que aparece de modo explícito, mas que não pode ser abordada de modo conseqüente sem sua inter-relação com as duas outras dimensões da violência, quais sejam, a simbólica e a sistêmica.

Por outro lado, referente à educação, Zizek (2013) ressalta que esta, cada vez mais, está mergulhada em uma profunda crise. Pois, o seu papel institucional relacionado à socialização e à produção e reprodução de conhecimentos, tende a se restringir prioritariamente à oferta de uma aprendizagem de habilidades voláteis voltadas para o exercício de tarefas flexíveis ligadas a ocupações específicas, demandadas pelo mercado de trabalho capitalista. Assim, a educação passa a adequar-se integralmente ao status quo, ao mesmo tempo em que a idéia de uma cultura educacional qualificada e universal passa a ser completamente abandonada.

Ademais, conforme Zizek (2013), as gerações de professores - que no passado eram verdadeiros pensadores e debatedores públicos dos problemas econômico-sociais,

\begin{tabular}{|l|l|l|l|l|}
\hline Q & Dovista \\
\hline
\end{tabular}


políticos e culturais - praticamente desapareceram. Estes professores foram substituídos por acadêmicos desencantadamente especialistas que trabalham de modo recluso e apático. Ou seja, as suas atividades não contemplam nenhum engajamento político efetivo, fora dos muros dos espaços acadêmicos. Seus discursos, além de estarem impregnados de jargões elitistas, estão embriagados por uma reflexividade racionalista reprodutora do sempre mesmo. A própria educação superior universitária perdeu o seu elo de conexão com abordagem crítica das contradições e das catástrofes sociais que afetam a maioria da população mundial, no cerne do capitalismo global contemporâneo.

No atual contexto, segundo Zizek (2011b), a educação privatizada e flexível substituiu em larga medida a educação pública e universal. O mercado invadiu a educação que antes era considerado domínio privilegiado do estado. E neste quadro as práticas educacionais não correspondem mais às necessidades e às aspirações da maioria da população. Assim, cabe reinventar a educação radicalmente.

A partir de uma perspectiva filosófica, o autêntico ato político - e, em consequiência, também, o cerne de todo ato pedagógico direcionado à emancipação individual e social - se reveste de uma autêntica radicalidade. Pois, não se trata de uma atividade falsa de impotência política que se restringe apenas em reproduzir a constelação sócio-simbólica do capitalismo global existente, mas se trata de uma ação política que está tencionada pelo Real impossível. Ademais, todo ato político e pedagógico radical se localiza além de toda a sua condicionalidade, ou seja, ele é incondicional. Assim, não se trata de um "ato incondicional" situado fora da história e fora do simbólico, mas simplesmente de um ato surpreendente que é irredutível ao parâmetro e à moldura das condições opressivas dadas.

Enfim, segundo Zizek (2011a), o ato político e o ato educativo com vistas à emancipação somente podem ocorrer quando o pensamento e a ação do sujeito se desprendem das coordenadas da rede simbólica alienante - sintonizada com a reprodução da forma social do capital - e se atam à atividade coletiva de emancipação. Somente, desse modo, eles podem traduzir-se em uma ação educativa e política soberana, sem fixação institucional imediata às imposições do "status quo". Ou seja, apenas assim eles estarão desatados das exigências pragmáticas de adaptação às diretrizes do poder constituído, as quais tendem a travar a emergência e a potência de uma linguagem, de um discurso e de uma práxis efetivamente de emancipação. Assim, o ato político-pedagógico crítico instaura sua própria legalidade, suspendendo a Lei do

\begin{tabular}{|c|c|c|c|}
\hline Qovista Dialectus & Ano 3 & n. 9 & Setembro - Dezembro 2016 \\
\hline
\end{tabular}


poder opressor imperante, abrindo espaços para a criatividade e a instauração de um processo de emancipação econômico-social, cultural e política.

\section{Referências bibliográficas:}

SAFATLE, Vladimir. Posfácio: A Política do Real de Slavoj Zizek. In: ZIZEK, Slavoj. Bem-vindo ao Deserto do Real. São Paulo, Boitempo Editorial, 2003, pp.179-191.

ZIZEK, Slavoj. Violência: Seis reflexões laterais. São Paulo, Boitempo, 2014.

_, Slavoj. Alguém Disse Totalitarismo? São Paulo, Boitempo Editorial, 2013.

, Slavoj. Em Defesa das Causas Perdidas. São Paulo, Boitempo, 2011a.

, Slavoj. Primeiro Como Tragédia, Depois Como Farsa. SP, Boitempo, 2011 b.

, Slavoj. O Sujeito Incômodo: O Centro Ausente da Ontologia Política. Lisboa, Relógio D’Água Editores, 2009a.

Slavoj. De La démocracie à la violence divine. In: Democracie, dans quel État?, Paris, La Fabrique Ed., 2009b.

, Slavoj. A Visão em Paralaxe. São Paulo, Boitempo Editorial, 2008.

Slavoj. Às Portas da Revolução: Seleção de Escritos de Lenin de fevereiro a outubro de 1917. São Paulo, Boitempo Editorial, 2005. 